\title{
Evaluation of enamel damages following orthodontic bracket debonding in fluorosed teeth bonded with adhesion promoter
}

\author{
Tahreh Baherimoghadam ${ }^{1}$, Sahar Akbarian ${ }^{2}$, Reza Rasouli ${ }^{3}$, Navid Naseri $^{4}$
}

Correspondence: Dr. Navid Naseri

Email: navidnaseri@gmail.com

\begin{abstract}
'Department of Orthodontics, School of Dentistry, Yasu University of Medical Sciences, Yasuj, Iran, 2Department of Operative Dentistry, School of Dentistry, Shiraz University of Medical Sciences, Shiraz, Iran,

${ }^{3}$ Department of Orthodontics, School of Dentistry, Shahed University of Medical Science, Tehran, Iran, ${ }^{4}$ Department of Orthodontics, School of Dentistry, Islamic Azad University, Shiraz, Iran
\end{abstract}

\section{ABSTRACT}

Objective: To evaluate shear bond strength (SBS) of the orthodontic brackets bonded to fluorosed and nonfluorosed teeth using Light Bond with and without adhesion promoters and compare their enamel damages following debonding. Materials and Methods: In this study, 30 fluorosed (Thylstrup and Fejerskov Index $=4-5$ ) and 30 nonfluorosed teeth were randomly distributed between two subgroups according to the bonding materials: Group 1, fluorosed teeth bonded with Light Bond; Group 2, fluorosed teeth bonded with adhesion promoters and Light Bond; Group 3, nonfluorosed teeth bonded with Light Bond; Group 4, nonfluorosed bonded with adhesion promoters and Light Bond. After bonding, the SBS of the brackets was tested with a universal testing machine. Stereomicroscopic evaluation was performed by unbiased stereology in all teeth to determine the amount of adhesive remnants and the number and length of enamel cracks before bonding and after debonding. The data were analyzed using two-way analysis of variance, Kruskal-Wallis, Wilcoxon Signed Rank, and Mann-Whitney test. Results: While fluorosis reduced the SBS of orthodontic bracket $(P=0.017)$, Enhance Locus Ceruleus LC significantly increased the SBS of the orthodontic bracket in fluorosed and nonfluorosed teeth $(P=0.039)$. Significant increasing in the number and length of enamel crack after debonding was found in all four groups. There were no significant differences in the length of enamel crack increased after debonding among four groups $(P=0.768)$ while increasing in the number of enamel cracks after debonding was significantly different among the four groups $(P=0.023)$. Teeth in Group 2 showed the highest enamel damages among four groups following debonding. Conclusion: Adhesion promoters could improve the bond strength of orthodontic brackets, but conservative debonding methods for decreasing enamel damages would be necessary.

Key words: Dental debonding, dental fluorosis, orthodontic bracket

\section{INTRODUCTION}

Bonding the orthodontic brackets in patients suffering from dental fluorosis remains a clinical problem due

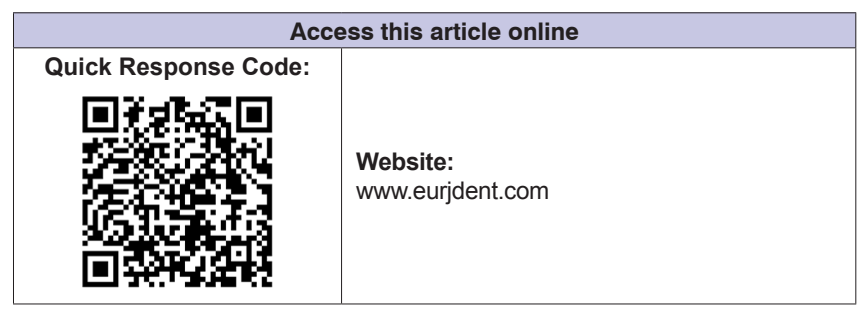

to bracket debonding at the enamel resin interface. ${ }^{[1,2]}$ Fluorosed teeth have a compromised structure and

This is an open access article distributed under the terms of the Creative Commons Attribution-NonCommercial-ShareAlike 3.0 License, which allows others to remix, tweak, and build upon the work non-commercially, as long as the author is credited and the new creations are licensed under the identical terms.

For reprints contact: reprints@medknow.com

How to cite this article: Baherimoghadam T, Akbarian S, Rasouli R, Naseri N. Evaluation of enamel damages following orthodontic bracket debonding in fluorosed teeth bonded with adhesion promoter. Eur $\mathrm{J}$ Dent 2016;10:193-8.

DOI: $10.4103 / 1305-7456.178296$ 
appearance. ${ }^{[3,4]}$ Fluorosed enamel present an outer hypermineralized and acid resistant layer which is accompanied by subsurface hypomineralization. ${ }^{[4-6]}$

In fluorosed teeth, grinding or microabrasion of the outer mineralized surface is recommended to improve the shear bond strength (SBS). ${ }^{[7,8]}$ Even so, microabrasion may result in ingestion of the powder, damaged enamel, and allergic reactions to aluminum oxide powder or silicon carbide; also, this method is time-consuming and more costly. ${ }^{[9]}$ Prolonged etching is also suggested to improve the SBS, [10-12] although predicting sufficient time for attaining surface roughness is difficult. ${ }^{[13]}$

Applying adhesion promoters such as Enhance Locus Ceruleus (LC) (Reliance, Itasca, Illinois, USA) is an alternative method for bonding the brackets to fluorosed teeth. ${ }^{[1,10,14]}$ Manufactures claim that Enhance LCimproves the adhesion of resins to fluorosed, hypocalcified, and primary teeth. Furthermore, these materials create a chemical bonding that may be more predictable. It composes of hydroxyethyl methacrylate (HEMA), tetrahydrofurfuryl cyclohexane dimethacrylate, and ethanol. The HEMA molecule contains two functional groups: Hydrophobic and hydrophilic. ${ }^{[15]}$ Hydrophilic monomers in the adhesive system facilitate the penetration of resin into etched enamel and decreases interfacial porosity; hence, incorporated hydrophilic resin improves bond strength. ${ }^{[16]}$ Although the efficacy of adhesion promoters on bond strength of brackets to enamel has been evaluated in several studies. ${ }^{[17,18]}$ As mentioned previously, increasing the SBS of orthodontic bracket would be necessary in fluorosed teeth as well. On the other hand, increasing bond strength could compromise the safety of debonding and may increase the enamel damage ${ }^{[19,20]}$ Bishara et al. believe that bond failure in enamel-adhesive interface could lead to irreversible damage on enamel surface. ${ }^{[21]}$ In some studies, it has been shown that adhesion promoters increase the SBS of the orthodontic brackets to fluorosed enamel, although their bond failure is seen within the enamel-adhesive surface. ${ }^{[1]}$

Therefore, the aim of this in vitro study was to compare the enamel damages and SBS following debonding brackets in fluorosed and nonfluorosed teeth bonded with and without adhesion promoters.

\section{MATERIALS AND METHODS}

\section{Classification of enamel fluorosis}

Sixty (30 fluorosed and 30 nonfluorosed) noncarious human upper permanent premolar teeth recently extracted for orthodontic reasons and without any caries or visible defects were selected and kept in thymol $0.1 \%$. Fluorosed teeth were collected from subjects living in endemic fluorosis regions. All teeth were from patients between 13 and 18-year-old and without previous treatment with $\mathrm{H}_{2} \mathrm{O}_{2}$ and $\mathrm{H}$-acid. Ethical permission was obtained from the Ethical Committee of Yasuj University of Medical Sciences. Two investigators observed teeth under stereomicroscope to ensure that there is no crack along their crown, they also evaluated the fluorosed teeth and classified them according to the Thylstrup and Fejerskov Index (TFI) that is based on clinical changes in fluorosed teeth. ${ }^{[6]}$

\section{Bonding procedure}

Before bonding, the buccal surface of all teeth was cleansed and polished by a water and nonfluoridated pumice mixture using a low-speed handpiece for $20 \mathrm{~s}$. The fluorosed and nonfluorosed teeth were divided into four groups of 15 teeth each according to the bonding procedure. Groups 1 and 2 consisted of fluorosed teeth while Groups 3 and 4 contained non fluorosed teeth.

In this study, 0.018 inch standard Dyna-Lock premolar brackets (3M Unitek, Monrovia, California, USA) were bonded. Each tooth was etched with 37\% phosphoric acid gel (Gel ETCH, 3M Unitek, Monrovia, California, USA) for $30 \mathrm{~s}$, rinsed for $20 \mathrm{~s}$, and air-dried for $5 \mathrm{~s}$. The enamel surface was left slightly moist according to the manufacturer's recommendation.

In Groups 1 and 3, Light Bond (Reliance, Itasca, IL, USA) was used as the orthodontic adhesive. A thin uniform layer of sealant was brushed on the enamel etched the surface and light cured for $10 \mathrm{~s}$ with LED curing unit $1500 \mathrm{mw} / \mathrm{cm}^{2}$ (Smart life IQ2, Dentsply-Milford, USA). Before applying the paste, a thin layer of sealant was also painted on the metal bracket base, and light cured for $10 \mathrm{~s}$. The paste (Reliance, Itasca, IL, USA) was placed onto the bracket base using a syringe; the bracket was placed on the enamel surface $4 \mathrm{~mm}$ far from buccal cusp of the tooth. An explorer was employed to seat the bracket on the enamel surface with a consonant force and excessive adhesive was removed. The bracket was cured with a visible light cure unit for $40 \mathrm{~s}$ ( $10 \mathrm{~s}$ on the distal, $10 \mathrm{~s}$ on the mesial, $10 \mathrm{~s}$ on the incisal, and $10 \mathrm{~s}$ on the gingival surface of the bracket).

In Groups 2 and 4, two layers of Enhance LC (Reliance, Itasca, IL, USA) were applied on the etched enamel surface and then air-dried gently. After applying Enhance LC, a thin layer of Light Bond sealant was painted on Enhance LC coated layer and light cured 
for $10 \mathrm{~s}$. The bracket was bonded in the position with Light Bond adhesive as previously described. After bonding, the specimens were kept in distilled water.

A jig (Jelenco Surveyor, USA) was applied to align the buccal surface of each specimen to the base of the cylinder when specimens were embedded in a cold cure acrylic resin. A universal testing machine (Zwick roll, Germany) was used at a crosshead speed of $0.5 \mathrm{~mm} / \mathrm{min}$ for shear bond testing. A knife-edge blade was positioned to produce a direct force to the bracket interface parallel to the axis of the tooth.

\section{Microscopic evaluation}

To determine the number and the length of enamel cracks a stereomicroscope (Nikon, SM 745T, Japan) at $\times 38$ magnification was employed before bonding [Figure 1a]. A digital camera (Nikon, SMZ 745T, Japan) connected to a stereomicroscope with software designed at Histomorphometry and Stereology Research Center (Shiraz, Iran) was also used. For same magnification in all samples, the distance from the buccal surface of specimens to the lens of the stereomicroscope should be equal; hence, a pair of laboratory and sculptural paste was used in this study. The sculptural paste was placed in one of the labs; the buccal surface of the teeth and the border of the laboratory were coincided by wrestling the other lab on the buccal surface of the teeth; using this procedure, the buccal surface of teeth and horizon will be parallel.

The cracks would not be recognized if the direction of the enamel crack and light are similar. To determine the number and the length of enamel cracks and their direction preciously, each specimen was rotated $360^{\circ}$ around the center point of the buccal surface.

After deboning, excessive composite on the enamel surface was removed using a low-speed handpiece and tungsten-carbide (Dentaurum 00-603-123) bur using water coolant parallel to the enamel surfaces. Stereomicroscope examination was repeated to compare the changes of the length and number of enamel cracks after debonding [Figure 1b].

\section{Adhesive Remnant Index}

All teeth were evaluated using a stereomicroscope at $\times 10$ magnification to determine the amount of adhesive resin according to the 4-point scale of Adhesive Remnant Index (ARI), ${ }^{[22]}$ ARI scores were graded as follows:

- 0: No adhesive left on the tooth surface

- 1: Less than half of the adhesive left on the tooth surface
- 2: More than half of the adhesive left on tooth surface

- 3: All adhesive left on the tooth surface.

\section{Statistical analysis}

Two-way analysis of variance (ANOVA) was applied to determine the impact of fluorosis, bonding material, and their interaction.

Kolmogorov-Smirnov normality test was used to determine whether the samples were conformed to a normal distribution. Nonparametric tests were used because quantitative variables were not normally distributed. Kruskal-Wallis test was used to determine the significant difference in the number and length of enamel cracks before bonding and after debonding among the four groups. To define significant increasing in the number and length of enamel cracks before and after debonding in each group, Wilcoxon Signed Ranks test was employed. Kruskal-Wallis test was performed to determine the significant difference in the number and length of enamel cracks after debonding among the four groups. Mann-Whitney test was used to compare the groups in the number of enamel cracks. To determine and compare the significant difference in ARI scores among four groups, Kruskal-Wallis test was used. Statistical significance was identified at $P<0.05$.

To ensure consistency between examiners in the classification of fluorosed teeth, a reproducibility test was used. The test of inter-examiner reproducibility resulted in a Cohen's Kappa statistic of 0.87 . Furthermore, all specimens were evaluated by two examiners for the number and the length of enamel cracks before bonding and after debonding. Inter-examiner reproducibility gave a Cohen's Kappa test of 0.92 . Data recorded by the first examiner were analyzed by the statistical test.

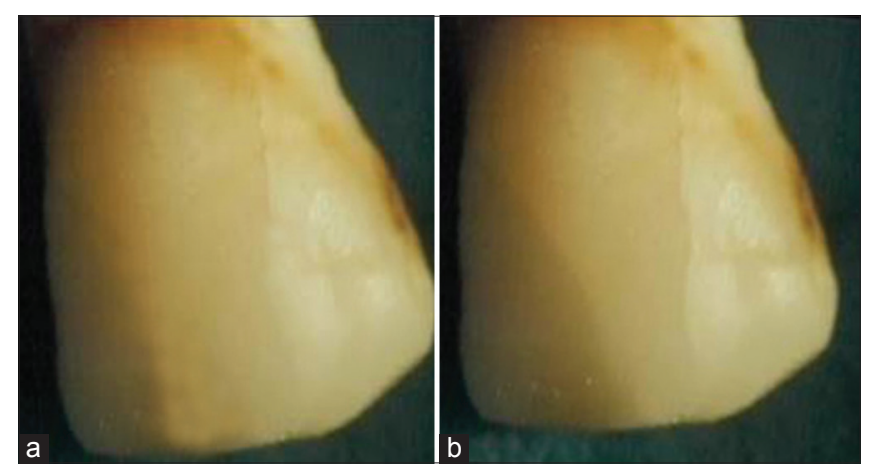

Figure 1: (a) Before bonding, stereomicroscopic view of the buccal surface before bonding. (b) After debonding, increase in the length of enamel crack 


\section{RESULTS}

The result of Two-way ANOVA demonstrated that adhesive type $(P=0.017)$ and fluorosis $(P=0.039)$ have a significant effect; whereas the interaction term was insignificant allowing the assignment of effect to individual parameters [Table 1].

The mean SBS and standard deviations for each group are given in Table 2. Group 1, fluorosed teeth bonded with Light Bond, showed lowest SBS (13.44 \pm 1.68 $\mathrm{MPa}$ ) among the four groups. Frequency distribution of the ARI scores and Kruskal-Wallis test comparison of the groups are presented in Table 3; there was significant differences among four groups $(P=0.030)$. No significant difference in the number $(P=0.950)$ and length $(P=0.949)$ of enamel cracks was found among four groups before bonding. The result of Wilcoxan test indicated that there was significant increasing in the number and length of enamel cracks after debonding in each group [Tables 4 and 5].

Comparison of the differences in the number and length of enamel crack increased after debonding among the four groups showed no significant differences in the length of enamel cracks increased after debonding among the four groups $(P=0.768)$; while, significant differences in the number of enamel cracks was observed after debonding among the four groups $(P=0.023)$ [Table 5]. The result of Mann-Whitney test defined that Group 2 (fluorosed teeth and Light Bond/Enhance LC) showed most increasing in the number of enamel crack.

\section{DISCUSSION}

The minimum bond strength of orthodontic brackets that is suggested to withstand normal orthodontic force is between 6 and $8 \mathrm{MPa} \cdot{ }^{[23]}$ However, noncompliant patients and fluorosed and hypocalcified teeth also need supplemental bond strength. ${ }^{[19]}$

The classification of fluorosis in this study was performed according to TFI score, which is based on clinical changes. ${ }^{[2]}$ The benefit of TFI is that it is consistent with histopathological changes in the enamel with high reproducibility. ${ }^{[25]}$ Only upper premolars were used in our study, specific type of tooth usage inhibits problems that are related with variation in fluoride content between different tooth types. ${ }^{[26]}$

Most studies regarding SBS in fluorosed teeth are based on those variables that evaluate enamel conditioning

\begin{tabular}{|c|c|c|c|c|c|}
\hline & $\begin{array}{l}\text { Type III } \\
\text { sum of } \\
\text { squares }\end{array}$ & Df & $\begin{array}{c}\text { Mean } \\
\text { square }\end{array}$ & F ratio & Significant $^{\mathrm{a}}$ \\
\hline Corrected model & $55.290^{\mathrm{b}}$ & 3 & 18.430 & 3.873 & $0.014^{*}$ \\
\hline Intercept & 3548.644 & 1 & 13548.644 & 2846.872 & $<0.001^{* *}$ \\
\hline Fluorosis & 28.732 & 1 & 28.732 & 6.037 & $0.017^{*}$ \\
\hline Bonding protocol & 21.361 & 1 & 21.361 & 4.488 & $0.039^{*}$ \\
\hline $\begin{array}{l}\text { Fluorosis } \times \\
\text { bonding protocol }\end{array}$ & 5.198 & 1 & 5.198 & 1.092 & 0.300 \\
\hline Error & 266.511 & 56 & 4.759 & & \\
\hline Total & 13870.446 & 60 & & & \\
\hline Corrected total & 321.802 & 59 & & & \\
\hline
\end{tabular}

$\begin{aligned} & \text { Table 2: Shear bond strength (SBS) and adhesive } \\
& \text { remnant index (ARI) scores for each group }\end{aligned}$
\begin{tabular}{llcr} 
Type of teeth & Type of material & $\begin{array}{c}\text { Shearbond } \\
\text { strength }\end{array}$ \\
\cline { 2 - 4 } & & Mean (MPa) & SD \\
\hline Fluorosed teeth & Light Bond & 13.44 & 1.68 \\
& Light Bond + Enhance LC & 15.22 & 2.07 \\
Non-fluorosed teeth & Light Bond & 15.41 & 2.66 \\
& Light Bond + Enhance LC & 16.02 & 2.20 \\
\hline
\end{tabular}

Table 3: Frequency of dhesive remnant index (ARI)
scores for each group

such as prolonged etching time, type of acid, and the mechanical removal of the outer hypermineralized layer. ${ }^{[9-12,27]}$

Enhance LC has been introduced as an adhesion promoter for specific use in orthodontics. Incorporation of hydrophilic monomers helps resin infiltration to the etched enamel and reduces interfacial porosity. This characteristic can improve bond strength and interfacial integrity; ${ }^{[17]}$ hence, adhesion promoter agents are suggested to improve bond strength. Contradictory results have been reported concerning the effect of adhesion promoters on bond strength of orthodontic to nonfluorosed teeth. The results of some studies show an increase in SBS of new or rebonded 
Baherimoghadam, et al.: Enamel damages following orthodontic bracket debonding

\begin{tabular}{|c|c|c|c|c|c|}
\hline Type of teeth & Type of material & $\begin{array}{c}\text { Before } \\
\text { mean } \pm S D\end{array}$ & $\begin{array}{c}\text { After } \\
\text { mean } \pm S D\end{array}$ & $\begin{array}{l}\text { Difference } \\
\text { mean } \pm S D\end{array}$ & $P$ value $^{\mathrm{a}}$ \\
\hline \multirow[t]{2}{*}{ Fluorosed teeth } & Light Bond & $1.60 \pm 0.83$ & $3.47 \pm 0.10$ & $1.87 \pm 0.91 \mathrm{~A}^{\mathrm{c}}$ & $0.001^{* *}$ \\
\hline & Light Bond + Enhance LC & $1.40 \pm 0.99$ & $4.40 \pm 0.99$ & $3.00 \pm 0.41 \mathrm{~B}$ & $0.001^{* *}$ \\
\hline \multirow[t]{2}{*}{ Non-fluorosed teeth } & Light Bond & $1.47 \pm 0.10$ & $2.93 \pm 1.03$ & $1.46 \pm 1.06 \mathrm{~A}$ & $0.003^{*}$ \\
\hline & Light Bond + Enhance LC & $1.53 \pm 0.74$ & $3.00 \pm 1.25$ & $1.47 \pm 1.52 \mathrm{~A}$ & $0.011^{*}$ \\
\hline$P$ value ${ }^{\mathrm{b}}$ & & 0.950 & $0.023^{*}$ & $0.010^{*}$ & \\
\hline
\end{tabular}

\begin{tabular}{|c|c|c|c|c|c|}
\hline Type of tooth & Type of material & $\begin{array}{c}\text { Before } \\
\text { mean } \pm S D\end{array}$ & $\begin{array}{c}\text { After } \\
\text { mean } \pm S D\end{array}$ & $\begin{array}{l}\text { Difference } \\
\text { mean } \pm S D\end{array}$ & $P$ value ${ }^{a}$ \\
\hline \multirow[t]{2}{*}{ Fluorosed teeth } & Light Bond & $4.06 \pm 26.30$ & $11.86 \pm 46.67$ & $7.80 \pm 4.53$ & $0.001^{* \star}$ \\
\hline & Light Bond + Enhance LC & $4.45 \pm 28.91$ & $12.12 \pm 18.36$ & $7.66 \pm 3.48$ & $0.001^{* *}$ \\
\hline \multirow[t]{2}{*}{ Non-fluorosed teeth } & Light Bond & $3.83 \pm 25.25$ & $10.47 \pm 22.50$ & $6.63 \pm 3.95$ & $0.001^{* *}$ \\
\hline & Light Bond + Enhance LC & $4.36 \pm 20.50$ & $11.37 \pm 19.65$ & $7.01 \pm 2.86$ & $0.001^{* *}$ \\
\hline$P$ value ${ }^{\mathrm{b}}$ & & 0.949 & 0.768 & 0.811 & \\
\hline
\end{tabular}

brackets, ${ }^{[28,29]}$ while others found acceptable levels of bond strength of the bonded brackets, ${ }^{[30]}$ and still others rejected the idea that the application of Enhance LC could increase the bond strength. ${ }^{[19,17,31]}$

The result of this study showed that while the fluorosis decreased the SBS of orthodontic brackets to fluorosed enamel which is in complete agreement with previous studies, ${ }^{[1,25]}$ Enhance LC improved the mean SBS in fluorosed and nonfluorosed teeth. This is in agreement with those studies which reported that Enhance LC improved the SBS of orthodontic brackets in nonfluorosed teeth. The effect of an adhesion promoter on fluorosed teeth have been tested in a few studies. Interestingly, Adanir et al. reported that Enhance LC significantly increases the bond strength of orthodontic brackets to fluorosed enamel. ${ }^{[1]}$

The result of this study based on the ARI revealed that failures mostly occurred at the enamel-adhesive interface in the groups bonded with Enhance LC, and these results were achieved in previous studies as well. ${ }^{[1]}$ Adanir et al. showed that the bonds created by adhesion promoters failed in a more unfavorable location than those created by conventional bonding agents. ${ }^{[1]}$ Although, no direct relation could be found between the SBS and the location of bond failure, bond failure at enamel-adhesive interface increases the shear force stress at the enamel surface and decreases the probability of undamaged enamel. ${ }^{[32]}$ Vicente et al. showed that enamel fractures following debonding in nonfluorosed teeth bonded with and without adhesion promoters; however, adhesion promoters are not recommended in adult patients presenting with enamel cracks and enamel defects, ${ }^{[17]}$ no study has done yet to evaluate the effect of adhesion promoters on enamel damages following debonding in fluorosed teeth. Hence, in our study, the enamel damages following debonding in fluorosed teeth have been tested as well.

In this study, enamel damages were determined by differences between enamel crack length and number before bonding and after debonding. The length and number of enamel cracks increased in all four groups after debonding, which is consistent with those studies that showed debonding as a destructive procedure in orthodontic treatment. ${ }^{[33]}$ In fluorosed teeth, the number of enamel cracks increased significantly in groups bonded with Enhance LC. However, no significant increase was found in the length of enamel cracks. It can be interpreted that the inner weak structure of hypoplastic enamel in fluorosed teeth show low resistance to enamel crack propagation, but the outer hypermineralized layer containing compact and brittle crystal of fluoridated hydroxyapatite and fluorapatite prevents the extension of enamel cracks.

In this study, although adhesion promoters significantly improved the bond strength of orthodontic brackets to fluorosed enamel, it also resulted in more enamel damages compared to conventional bonding method. It has been shown that there is a tendency for fractures to occur when bond strength exceeds a certain threshold. ${ }^{[17]}$ Newman et al. indicated that adhesion promoters are not a good recommendation for patients with enamel defects. ${ }^{[34]}$ 
In fluorosed teeth, most studies just focus on improving of SBS of orthodontic brackets. However, preserving tooth structure and preventing irreversible damages after debonding must be considered as much as improving bond strength.

\section{CONCLUSION}

- Fluorosis significantly reduces SBS of orthodontic bracket. While, adhesion promoters improve SBS of orthodontic brackets in fluorosed and nonfluorosed teeth

- Significant increasing in the number and length of enamel cracks was observed among four groups following debonding

- Increasing in the number of enamel cracks after debonding was significantly different among the four groups, whereas no significant differences in the length of enamel crack increased was observed among four groups after debonding

- There is a significant increase in the number of enamel crack with the use of adhesion promoters.

\section{Financial support and sponsorship}

Nil.

\section{Conflicts of interest}

There are no conflicts of interest.

\section{REFERENCES}

1. Adanir N, Türkkahraman H, Yalçin Güngör A. Effects of adhesion promoters on the shear bond strengths of orthodontic brackets to fluorosed enamel. Eur J Orthod 2009;31:276-80.

2. Miller RA. Bonding fluorosed teeth: New materials for old problems. J Clin Orthod 1995;29:424-7.

3. Adanir N, Türkkahraman H, Güngör AY. Effects of fluorosis and bleaching on shear bond strengths of orthodontic brackets. Eur J Dent 2007;1:230-5.

4. DenBesten PK. Biological mechanisms of dental fluorosis relevant to the use of fluoride supplements. Community Dent Oral Epidemiol 1999;27:41-7.

5. Gungor AY, Turkkahraman H, Adanir N, Alkis H. Effects of fluorosis and self etching primers on shear bond strengths of orthodontic brackets. Eur J Dent 2009;3:173-7.

6. Fejerskov O, Larsen MJ, Richards A, Baelum V. Dental tissue effects of fluoride. Adv Dent Res 1994;8:15-31.

7. Duan $\mathrm{Y}, \mathrm{Chen} \mathrm{X}, \mathrm{Wu}$ J. Clinical comparison of bond failures using different enamel preparations of severely fluorotic teeth. J Clin Orthod 2006;40:152-4.

8. Ermis RB, De Munck J, Cardoso MV, Coutinho E, Van Landuyt KL, Poitevin A, et al. Bonding to ground versus unground enamel in fluorosed teeth. Dent Mater 2007;23:1250-5.

9. Noble J, Karaiskos NE, Wiltshire WA. In vivo bonding of orthodontic brackets to fluorosed enamel using an adhesion promotor. Angle Orthod 2008;78:357-60.

10. Opinya GN, Pameijer CH. Tensile bond strength of fluorosed Kenyan teeth using the acid etch technique. Int Dent J 1986;36:225-9.

11. Al-Sugair MH, Akpata ES. Effect of fluorosis on etching of human enamel. J Oral Rehabil 1999;26:521-8.

12. Zavala-Alonso V, Aguilera-Flores R, Patiño-Marin N,
Martinez-Castañon GA, Anusavice KJ, Loyola-Rodriguez JP Nanostructure evaluation of healthy and fluorotic dentin by atomic force microscopy before and after phosphoric acid etching. Dent Mater J 2011;30:546-53.

13. Torres-Gallegos I, Zavala-Alonso V, Patiño-Marín N, Martinez-Castañon GA, Anusavice K, Loyola-Rodríguez JP. Enamel roughness and depth profile after phosphoric acid etching of healthy and fluorotic enamel. Aust Dent J 2012;57:151-6.

14. Wiltshire WA, Gorbonos M, Botha SJ. An adhesion promoter for improved bonding to fluorosed teeth in orthodontics. J Dent Res 1996;75:1247.

15. Nakabayashi N, Kojima K, Masuhara E. The promotion of adhesion by the infiltration of monomers into tooth substrates. J Biomed Mater Res 1982;16:265-73.

16. Hotta K, Mogi M, Miura F, Nakabayashi N. Effect of 4-MET on bond strength and penetration of monomers into enamel. Dent Mater 1992;8:173-5.

17. Vicente A, Bravo LA, Romero M, Ortíz AJ, Canteras M. Bond strength of brackets bonded with an adhesion promoter. Br Dent J 2004;196:482-5.

18. Vicente A, Bravo LA, Romero M, Ortíz AJ, Canteras M. Effects of 3 adhesion promoters on the shear bond strength of orthodontic brackets: An in-vitro study. Am J Orthod Dentofacial Orthop 2006;129:390-5.

19. Bishara SE, Fehr DE, Jakobsen JR. A comparative study of the debonding strengths of different ceramic brackets, enamel conditioners, and adhesives. Am J Orthod Dentofacial Orthop 1993;104:170-9.

20. Salehi P, Pakshir H, Naseri N, Baherimoghaddam T. The effects of composite resin types and debonding pliers on the amount of adhesive remnants and enamel damages: A stereomicroscopic evaluation. J Dent Res Dent Clin Dent Prospects 2013;7:199-205.

21. Bishara SE, Olsen ME, Von Wald L. Evaluation of debonding characteristics of a new collapsible ceramic bracket. Am J Orthod Dentofacial Orthop 1997;112:552-9.

22. Artun J, Bergland S. Clinical trials with crystal growth conditioning as an alternative to acid-etch enamel pretreatment. Am J Orthod 1984;85:333-40.

23. Reynolds JR. A review of direct orthodontic bonding. Br J Orthod 1975;2:171-8.

24. Thylstrup A, Fejerskov O. Clinical appearance of dental fluorosis in permanent teeth in relation to histologic changes. Community Dent Oral Epidemiol 1978;6:315-28.

25. Weerasinghe DS, Nikaido T, Wettasinghe KA, Abayakoon JB, Tagami J. Micro-shear bond strength and morphological analysis of a self-etching primer adhesive system to fluorosed enamel. J Dent 2005;33:419-26.

26. Knoll M, Gwinnett AJ, Wolff MS. Shear strength of brackets bonded to anterior and posterior teeth. Am J Orthod 1986;89:476-9.

27. Ateyah N, Akpata E. Factors affecting shear bond strength of composite resin to fluorosed human enamel. Oper Dent 2000;25:216-22.

28. Vijayakumar A, Venkateswaran S, Krishnaswamy NR. Effects of three adhesion boosters on the shear bond strength of new and rebonded brackets - An in vitro study. World J Orthod 2010;11:123-8.

29. Chung CH, Fadem BW, Levitt HL, Mante FK. Effects of two adhesion boosters on the shear bond strength of new and rebonded orthodontic brackets. Am J Orthod Dentofacial Orthop 2000;118:295-9.

30. Schaneveldt S, Foley TF. Bond strength comparison of moisture-insensitive primers. Am J Orthod Dentofacial Orthop 2002;122:267-73.

31. Wenger NA, Deacon S, Harradine NW. A randomized control clinical trial investigating orthodontic bond failure rates when using Orthosolo universal bond enhancer compared to a conventional bonding primer. J Orthod 2008;35:27-32.

32. Olsen ME, Bishara SE, Damon P, Jakobsen JR. Evaluation of Scotchbond multipurpose and maleic acid as alternative methods of bonding orthodontic brackets. Am J Orthod Dentofacial Orthop 1997;111:498-501.

33. KnöselM, Mattysek S, Jung K, Sadat-Khonsari R, Kubein-Meesenburg D, Bauss $\mathrm{O}$, et al. Impulse debracketing compared to conventional debonding. Angle Orthod 2010;80:1036-44.

34. Newman GV, Newman RA, Sun BI, Ha JL, Ozsoylu SA. Adhesion promoters, their effect on the bond strength of metal brackets. Am J Orthod Dentofacial Orthop 1995;108:237-41. 